\title{
EDITORIAL
}

\section{LA NUEVA POLÍTICA COMERCIAL DE LA UNIÓN EUROPEA DESBORDA EL MARCO DE SUS COMPETENCIAS. COMENTARIOS PRELIMINARES AL DICTAMEN 2/15 DEL TJUE}

The new trade policy of the European Union goes beyond the scope of its powers. Preliminary comments to Opinion 2/15 of the ECJ

\author{
JAVIER DÍEZ-HOCHLEITNER' \\ javier.diez-hochleitner@uam.es
}

Cómo citar/Citation

Díez-Hochleitner, J. (2017).

La nueva política comercial de la Unión Europea desborda

el marco de sus competencias. Comentarios preliminares

al Dictamen 2/15 del TJUE.

Revista de Derecho Comunitario Europeo, 57, 403-429. doi: https://doi.org/10.18042/cepc/rdce.57.01

\section{INTRODUCCIÓN}

La nueva Política Comercial Común (PCC), impulsada por la Comisión Europea a partir de su comunicación «Una Europa global: competir en el mundo» [COM (2006) 567 final], ha dado lugar a un importante programa de negociación de acuerdos de libre comercio (ALC) muchos más ambiciosos

1 Catedrático de Derecho Internacional Público de la Universidad Autónoma de Madrid. 
en sus objetivos. A esta nueva generación de ALC responde no solo el polémico proyecto de Transatlantic Trade and Investment Partnership (TTIP) con Estados Unidos sino, igualmente, el Comprehensive and Economic Trade Agreement (CETA), firmado con Canadá el 30 de octubre de 2016, o el ALC con la República de Singapur, cuyas negociaciones concluyeron en octubre de 2014. Basta con leer los índices de estos dos últimos textos para advertir que, a través de estos nuevos ALC, la Unión Eropea (UE) persigue una amplia y efectiva apertura de otros mercados para el conjunto de los productores de bienes y servicios y de los inversores europeos, apertura que solo es posible en condiciones de reciprocidad y que, por lo tanto, exige asegurar que se produzca en un marco que asegure, entre otros aspectos, la libre competencia y el respeto de los estándares europeos de protección en los ámbitos social, sanitario y medioambiental.

Se entiende así que, por ejemplo, el CETA, que ocupa más de 1500 páginas (en la versión que ha hecho pública la Comisión) abarque no solo todos los aspectos que atañen la liberalización del comercio de bienes (acceso al mercado, tratamiento nacional, prácticas desleales, barreras técnicas, medidas sanitarias y fitosanitarias, régimen aduanero, subsidios), sino igualmente del comercio de servicios (incluidos los servicios legales, el transporte, las telecomunicaciones, el turismo e, incluso, los servicios financieros), la libertad de establecimiento (libre acceso de las inversiones), la protección de las inversiones, el comercio electrónico, el acceso a los mercados públicos (contratación pública), así como otros aspectos transversales tales como la libre competencia entre empresas, la protección de la propiedad intelectual (incluidas las denominaciones de origen) o la consecución de un desarrollo sostenible. También que incluya numerosas disposiciones que buscan articular un marco institucional de cooperación, que incluye la llamada "cooperación regulatoria». El Acuerdo con Singapur abarca asimismo todas las materias que son objeto del CETA, si bien el alcance de las obligaciones acordadas es naturalmente más limitado.

El proceso de celebración del CETA y del Acuerdo con Singapur se ha visto salpicado, como no podía ser de otro modo, por una viva polémica entre la Comisión Europea, por una parte, y el Consejo y los Estados miembros, por otra, sobre la existencia o no de una competencia exclusiva de la UE para su firma y conclusión definitiva. La Comisión finalmente admitió (y propuso) que el CETA fuera firmado como «acuerdo mixto». Sin embargo, previamente (el 10 de julio de 2015), en relación con el Acuerdo con Singapur, solicitó al Tribunal de Justicia (TJUE) que se pronunciara sobre su posible conclusión como acuerdo "puramente comunitario». En concreto, la Comisión solicitó al Tribunal que señalara qué disposiciones del Acuerdo entran dentro de la competencia exclusiva de la UE y cuáles dentro de su competencia compartida y que indicara si contiene alguna disposición que corresponda a un ámbito de competencia 
exclusiva de los Estados miembros. El Dictamen 2/15 se hizo público el pasado 16 de mayo y, como muchos esperábamos, exige que el Acuerdo sea celebrado por la UE conjuntamente con los Estados miembros, esto es, como acuerdo mixto. Pero si el resultado no ha causado sorpresa, no cabe decir lo mismo de algunas de las conclusiones alcanzadas. En todo caso, se trata de un dictamen de indudable relevancia que pone de relieve, una vez más, no solo la complejidad del sistema competencial comunitario (complejidad que ya se evidenció en las conclusiones de la abogada general Eleanor Sharpston, presentadas el pasado 21 de diciembre, cuya extensión superó todas las expectativas), sino que el marco constitucional de la UE va siempre a la zaga de la realidad. ¿ $\mathrm{O}$ acaso es razonable que el diseño de la PCC quede encorsetado por dicho marco? Y en todo caso, ¿pueden la Unión y los Estados miembros permitírselo?

No podemos, sin embargo, pasar por alto que en su Dictamen 2/15 el Pleno del TJUE solo excluye del ámbito de las competencias exclusivas de la UE - para situarlas en el de las competencias compartidas y en el de las competencias exclusivas de los Estados miembros, respectivamente- las disposiciones del capítulo 9 del Acuerdo con Singapur relativas a las inversiones distintas de las directas (esto es, las inversiones «en cartera») y sobre arreglo de diferencias entre una parte e inversores de otra parte (es decir, la regulación que el acuerdo ofrece en materia de protección de inversiones). En sus conclusiones, la abogada general (AG) había propuesto situar también en el ámbito de las competencias compartidas las disposiciones relativas: al comercio de servicios de transporte aéreo, marítimo y por vías navegables; a la contratación pública en la medida en que se apliquen a los servicios de transporte; a aspectos no comerciales de los derechos de propiedad intelectual e industrial, y a la asunción de compromisos en materia laboral y medioambiental. Naturalmente, también concluía que corresponden a un ámbito de competencia compartida las disposiciones generales e institucionales en la medida en que afectaran a las disposiciones anteriormente referidas. Por otra parte, la AG sostuvo que la disposición contenida en el Acuerdo que preveía la terminación de los acuerdos bilaterales de protección de inversiones celebrados (APPRI) por los Estados miembros con Singapur afecta a una competencia exclusiva de los Estados miembros.

Con carácter general, cabe afirmar que el TJUE se decanta, como en otros pronunciamientos anteriores, por una interpretación extensiva del ámbito de aplicación tanto del art. 207.1 en materia de política comercial como a una aplicación generosa de la «doctrina AETR» consagrada en el art. 3.2 TFUE, pero siguiendo siempre la senda marcada en otros dictámenes y sentencias previas, algunas de ellas muy recientes (como es la sentencia Daiichi, a la que luego nos referiremos). En efecto, no se advierte en el Dictamen $2 / 15$, a mi juicio y con la salvedad que luego mencionaré, ningún intento 
por articular nuevas construcciones teóricas tendentes a ensanchar el alcance de la competencia exclusiva de la UE en sus relaciones exteriores, sino un productivo aprovechamiento de su jurisprudencia anterior. Y es precisamente este apego a su jurisprudencia anterior lo que le lleva, como veremos, a afirmar que las inversiones «en cartera» corresponden a un ámbito de competencia compartida de la Unión con fundamento en el segundo supuesto del art. 216.1 del TFUE.

Ahora bien, en relación con esta materia (inversiones «en cartera»), el TJ no aclara si el hecho de que corresponda a un ámbito de competencia compartida impide, por si solo, que el Acuerdo sea celebrado como "puramente comunitario». La jurisprudencia anterior apunta a una respuesta afirmativa, como así lo confirmó la sentencia de 2006 en el asunto MOX plant $^{2}$. Y es que, como señalara el AG Wahl en sus conclusiones relativas al Dictamen 3/15, "la elección entre un acuerdo mixto y acuerdo exclusivamente de la Unión, cuando la materia del acuerdo forma parte de un ámbito de competencia compartida [...], forma parte generalmente de 1 margen de apreciación del legislador de la Unión», siendo así que sólo habrá de ser mixto si incluye disposiciones que corresponden a competencias exclusivas de los Estados y que no tengan carácter accesorio ${ }^{3}$. Esta misma posición ha sido reiterada por el AG Szpunar en sus recientes conclusiones en el asunto Alemania c. Consejo $0^{4}$, estando pendiente que el TJ se pronuncie (en su caso). Nótese a este respecto que el Dictamen 2/15 confirma que el segundo supuesto del art. 216.1 del TFUE no se corresponde con el contemplado en el segundo supuesto del art. 3.2 del Tratado, que configura como un caso de competencia exclusiva aquel en que la celebración de un acuerdo por la UE sea necesaria "para ejercer su competencia interna». Esta tesis de la «mixicidad facultativa» (frente a «mixicidad obligatoria» que se daría si el acuerdo cubre competencias exclusivas tanto de la UE como de los Estados miembros), desarrollada por Alan Rosas ${ }^{5}$, no es ni siquiera mencionada en el Dictamen 2/15.

Una mención aparte merecen sus consideraciones en relación con el mecanismo de arreglo de controversias sobre inversiones entre una parte y los

2 Sentencia de 30 de mayo de 2006, Comisión c. Irlanda, MOX Plant, C-459/63, ECLI:EU:C:2006:345, apartado 95.

3 Conclusiones de 8 de septiembre de 2016, ECLI:EU:C:2016:657, puntos 119 ss.

4 Conclusiones de 24 de abril de 2017,C-600/14, ECLI:EU:C:2017:296, puntos 84 y ss.

5 Alan ROSAS, «Mixed Union-Mixed Agreements», en Martti KOSKENNIEMI (ed.), International Law Aspects of the European Union, Kluwer Law International, 1998, pp. 125-148 (en pp. 132 y ss.). 
inversores de la otra parte, así como respecto de la previsión de terminación de los APPRI celebrados con Singapur. En relación con el primer punto, la parquedad de la argumentación que ofrece el TJUE, afirmando que al sustraer diferencias a la competencia de los órganos jurisdiccionales de los Estados miembros, dicho mecanismo no puede establecerse sin el consentimiento de dichos Estados y que, por ello, el capítulo 9 que lo regula corresponde a una competencia compartida de la UE (apdos. 292-293), invita a pensar que no pudo (pero tal vez quiso) resolver de otro modo. Adviértase que el Dictamen resulta confuso en este punto pues si bien sitúa el mecanismo en un ámbito de competencia compartida apunta sin embargo a que está en juego una competencia exclusiva de los Estados miembros (razón por la cual sería necesario que el Acuerdo cuente con su consentimiento y, por tanto, que se configure como mixto), lo que podría inducir a pensar que, a juicio del TJ, competencias compartidas y mixicidad no son cosas distintas ${ }^{6}$. Y respecto de la cláusula sobre terminación de los APPRI anteriores, su conclusión (esta sí, novedosa por completo) basada en que la UE habría «sucedido" a los Estados miembros en ellos, resulta a mi juicio insostenible.

En las páginas que siguen analizaré el dictamen agrupando las consideraciones del TJUE en torno a tres grupos de disposiciones del Acuerdo: aquellas que, a su juicio, corresponden al ámbito de la PCC; las que quedarían, también a su juicio, absorbidas en el campo de las competencias exclusivas de la UE por el juego de la «doctrina AETR»; y las contenidas en el capítulo de inversiones, que el TJUE sitúa en parte dentro del alcance de la PCC y en parte en el ámbito de las competencias compartidas.

\section{EL ÁMBITO DE LA POLÍTICA COMERCIAL COMÚN}

\section{COMERCIO INTERNACIONAL DE MERCANCÍAS}

Al examinar qué disposiciones del Acuerdo con Singapur entran dentro del ámbito de la PCC (art. 207.1 TFUE), el Dictamen 2/215 comienza afirmando que «un acto de la Unión forma parte de esta política cuando tenga como objeto específico ese comercio, en la medida en que esté dirigido, en lo esencial, a promoverlo, facilitarlo o regularlo y produzca efectos directos e inmediato en él» (apdo. 36). El Dictamen confirma así la jurisprudencia del TJUE, que establece una doble condición para considerar que un acto

6 En sus conclusiones en el asunto Alemania c. Consejo, antes cit., el AG Szpunar se refiere precisamente a la necesidad de diferenciar ambos conceptos (en punto 83). 
de la UE entra dentro del ámbito de la PCC: que su objeto específico sea el comercio internacional y que produzca efectos directos e inmediatos en dicho comercio.

Si bien puede entenderse que la exigencia de este doble requisito está presente en la jurisprudencia del TJUE desde su sentencia de 12 de diciembre de 2002, asunto Comisión/Consejo, se explicita con plena nitidez en pronunciamientos posteriores, entre los que destacan la sentencia de 2013 Daiichi Sankyo y el reciente Dictamen 3/157. No basta, desde luego, con que el acuerdo considerado tenga repercusiones sobre el comercio internacional, como señalara el Dictamen 2/00 relativa al Convenio sobre la Diversidad Biológica ${ }^{8}$. Y poco importa, claro está, que su ejecución exija la adopción de medidas internas con fundamento en otras bases jurídicas del TFUE, como advirtió el Dictamen 1/94 en relación con el Acuerdo sobre la Agricultura anejo al Acuerdo de la OMC?.

Cuestión distinta es que, como señala el apdo. 6 del art. 207, el ejercicio de la competencia externa en materia de política comercial no pueda comportar ningún cambio en la delimitación de las competencias entre la UE y sus Estados miembros en otros ámbitos, y que no puede conllevar una armonización de las disposiciones legales o reglamentarias de los Estados miembros en la medida en que los Tratados excluyan dicha armonización.

No hemos de olvidar, por otra parte, que es jurisprudencia constante del TJUE que cuando el objeto de un acuerdo presenta varios componentes de los cuales uno es preponderante, siendo los otros meramente accesorios, su celebración debe fundarse en la base jurídica que corresponde a aquel ${ }^{10}$.

Partiendo de esta jurisprudencia, el Dictamen 2/15 concluye que los capítulos 2 a 6 del Acuerdo, relativos al «trato nacional y acceso de mercancías al mercado», a las «soluciones comerciales» (medidas antidumping y compensatorias y medidas de salvaguardia), a los «obstáculos técnicos al comercio», a

7 Sentencias de 12 de diciembre de 2002, Comisión/Consejo, C-281/01, EU:C:2002:761, apdos. 40-42, y de 18 de julio de 2013, Daiichi Sankyo, Daiichi Sankyo y Sanofi-Aventis Deutschland, C-414/11, EU:C:2013:520, apdo. 41, y el reciente Dictamen 3/15 relativo al Tratado de Marrakech sobre el acceso a las obras publicadas, de 14 de febrero de 2017, ECLI:EU:C:2017:114, apdo. 61.

8 Dictamen 2/00, de 6 de diciembre de 2001, EU:C:2001:664, apdo. 40.

9 Dictamen 1/94, sobre el Acuerdo por el que se establece la Organización Mundial de Comercio, de 15 de noviembre de 1994, EU:C:1994:384, apdo. 29.

10 Dictamen 1/08 sobre la modificación de las listas de compromisos específicos de la Comunidad y de sus Estados miembros en el ámbito del Acuerdo General sobre el Comercio de Servicios (AGCS), de 30 de noviembre de 2009, EU:C:2009:73, apdo. 62. 
las «medidas sanitarias y fitosanitarias» y a «aduanas y facilitación del comercio», entran dentro del ámbito del PCC y, por lo tanto, corresponden a una competencia exclusiva de la UE. Lo mismo cabe decir respecto del capítulo 7 , titulado "Obstáculos no arancelarios al comercio y a la inversión en generación de energías renovables», respecto del cual el TJUE señala que no contiene normas medioambientales, sino que impone a las partes obligaciones dirigidas a abrir el mercado (apdo. 73).

Esta conclusión resulta pacífica, incluso a la luz de la jurisprudencia anterior al Tratado de Lisboa. De hecho, en relación con los seis primeros capítulos del Acuerdo solo se cuestionó durante el procedimiento (por un Estado miembro) que la PCC cubriera las disposiciones sobre cooperación aduanera del capítulo 6, aduciendo que, al definir los objetivos de la PCC, el art. 206 TFUE se refiere al establecimiento de una unión aduanera «de conformidad con los arts. 28 a 32», sin mencionar el art. 33 del mismo Tratado (que precisamente versa sobre la cooperación aduanera). La AG, con razón, calificó este argumento de "formalista» (puntos 151-152), recordando que el dictamen 1/94 ya consideró que el antiguo art. 133 TCE cubría disposiciones análogas del GATT de 1994 y de los acuerdos del Anexo $1 \mathrm{~A}^{11}$.

Ahora bien, no podemos dejar de apuntar que la configuración del ámbito de la PCC a partir de la doble exigencia antes referida otorga un amplio margen de apreciación — si no de discrecionalidad - al propio TJUE. Este amplio margen de apreciación/discrecionalidad debería a mi juicio comportar una obligación de motivación reforzada en sus pronunciamientos, en particular, a partir de análisis económicos contrastados (que se echan de menos en el Dictamen 2/15). Sobre esta cuestión volveremos más tarde, no sin antes advertir que, con todo, en el caso de los capítulos del Acuerdo a que nos hemos referido no parece que puedan plantearse serias dudas sobre su carácter comercial y sus posibles efectos en el comercio.

\section{COMERCIO DE SERVICIOS}

El Dictamen 2/15 también afirma que las disposiciones del capítulo 8 del Acuerdo titulado «Servicios, establecimiento y comercio electrónico» (incluidas las relativas a los servicios financieros y al reconocimiento mutuo de cualificaciones profesionales) entran dentro del ámbito el art. 207.1 TFUE, a salvo de las relativas al ámbito de los transportes, considerando que cumplen con los dos requisitos anteriormente señalados (que su objeto específico sea el

11 Dictamen 1/94, cit., apdo. 34. 
comercio internacional y que produzca efectos directos e inmediatos en dicho comercio).

Como se recordará, en su Dictamen 1/94 el TJUE declaró que solo el suministro transfronterizo que no entraña el traslado de personas (modo de suministro 1) podía asimilarse al comercio de mercancías y entraba, por lo tanto, en el ámbito del antiguo art. $133 \mathrm{TCE}^{12}$. Ahora bien, en su Dictamen $1 / 08$, antes citado, entendió que el párrafo primero del apdo. 5, introducido en el art. 133 TCE por el Tratado de Niza, extendió el ámbito de la PCC a los modos de suministro 2 a 4, que el Acuerdo General de Comercio de Servicios de la OMC (AGCS) denomina, respectivamente, "consumo en el extranjero» (suministro en el territorio de un miembro de la OMC a un consumidor de servicios de cualquier otro miembro), "presencia comercial» (suministro por un proveedor de servicios a un miembro de la OMC mediante presencia comercial en el territorio de cualquier otro miembro) y "presencia de personas físicas» (suministro por un proveedor de servicios de un miembro de la OMC mediante la presencia de personas físicas en el territorio de cualquier otro miembro $)^{13}$, si bien incluyó una excepción respecto del comercio de servicios en determinados sectores (culturales, audiovisuales, servicios de educación, servicios sociales y salud humana), que el precepto configuró como de competencia compartida. Pues bien, el Dictamen 2/15 señala que la interpretación dada en relación con el art. 133.5 del TCE, referido al "comercio de servicios», es extrapolable al concepto de «intercambio de servicios» a que se refiere el art. 207.1 del TFUE (apdo. 54), precepto que además no contiene ninguna excepción sectorial.

Ahora bien, respecto del suministro de servicios en el ámbito del transporte, el TJUE recuerda que en su dictamen 1/08 ya señaló que el párrafo tercero del art. 133.6 TCE - cuyo contenido corresponde al del actual apartado 5 del art. 207 TFUE - pretendía mantener, en el ámbito de la PCT, «el paralelismo originario entre la competencia interna que se ejerce a través de la adopción unilateral de normas comunitarias y la competencia externa que se ejerce mediante la celebración de acuerdos internacionales, pues una y otra se mantienen ancladas, como antes, en el título del Tratado correspondiente, en particular, a la política común de transportes» ${ }^{14}$.

Sin embargo, el TJUE recuerda que, de acuerdo con su jurisprudencia anterior, no todas las disposiciones del Acuerdo con Singapur sobre transportes quedan fuera del ámbito de la PCC, sino únicamente aquellas que no

12 Ibid., apdos. 44-45.

13 Dictamen 1/08, cit., apdo. 119.

14 Ibid., apdo. 164. 
se refieran a la actividad física de desplazamiento de personas o mercancías de un lugar a otro por uno de esos modos de transporte de un «o cualquier servicio ligado a dicha actividad de forma inherente» ${ }^{15}$. $\mathrm{Y}$ a este respecto, contrariamente a la posición de la AG (punto 191), descarta que los servicios de reparación y mantenimiento de aeronaves (durante los cuales son retiradas del servicio) y los servicios de venta, comercialización o reserva de servicios de transporte aéreo estén ligados de forma inherente a los servicios del transporte, sino que forman parte de los servicios a que se refiere al art. 207.1 TFUE (apdos. 66-69).

En cuanto a los servicios excluidos de la PCC en virtud del art. 207.5 TFUE, el Dictamen analiza si no obstante ello puede considerarse que corresponden a un ámbito de competencia exclusiva de la UE en virtud de la llamada "doctrina AETR», aspecto sobre el que volveremos más tarde.

\section{ASPECTOS COMERCIALES DE LA PROPIEDAD INTELECTUAL E INDUSTRIAL}

Aplicando el doble test del objeto y del efecto, el TJUE también considera en su Dictamen 2/15 que todo el capítulo 11 del Acuerdo, relativo a la propiedad intelectual e industrial, está incluido en el ámbito de la PCP y que corresponde por ello a un ámbito de competencia exclusiva de la Unión. En efecto, entiende que el «objeto esencial» de dicho capítulo es facilitar y regular el comercio entre la UE y Singapur y que sus disposiciones pueden efectos directos e inmediatos en él (apdo. 130).

Por lo que se refiere al primer aspecto, el TJUE concluye que en la medida en que el conjunto de las disposiciones de dicho capítulo tiene por objeto "garantizar a los empresarios de la UE y de Singapur «un nivel adecuado» de protección de sus derechos de propiedad intelectual e industrial» permiten a dichos empresarios «disfrutar, en el territorio de la otra Parte, de estándares de protección de los derechos de propiedad intelectual e industrial que presentan una cierta homogeneidad y contribuyen así a su participación en igualdad de condiciones en el libre comercio de mercancías y de servicios entre la Unión y la República de Singapur» (apdos. 121-122). El TJUE extiende estas mismas consideraciones a las disposiciones por las que las partes se obligan a establecer procedimientos y recursos civiles y administrativos para que los interesados puedan hacer valer sus derechos de propiedad intelectual e industrial, así como las que exigen articular mecanismos de control aduanero para proteger

15 Sentencia de 15 de octubre de 2015, Grupo Itevelsa, C-168/14, ECLI:EU:C:2015: 685, apdo. 46. 
a sus titulares frente a la entrada de mercancías falsificadas o pirateadas (apdos. 123-124).

En cuanto a sus posibles efectos sobre el comercio internacional, el TJUE considera suficiente con remitirse a las conclusiones de la $A G$, quien a su vez se refiere a las conclusiones presentadas en relación con el Dictamen 3/15 (Tratado de Marrakech). En estas conclusiones Wahl afirmó que los derechos exclusivos que confieren las normas en materia de propiedad intelectual e industrial «no son sino formas sui generis de monopolios que pueden limitar la libre circulación de bienes y servicios", de manera que "por su propia naturaleza, las normas de propiedad intelectual están en su mayoría relacionadas con el comercio»" ${ }^{16}$.

El Dictamen 1/94 llegó, sin embargo, a la conclusión contraria. En efecto, en él se afirma que:

Ciertamente, existe un vínculo entre la propiedad intelectual y el comercio de mercancías. Los derechos de la propiedad intelectual permiten a sus titulares impedir a terceros llevar a cabo ciertos actos. Poder prohibir el uso de una marca, la fabricación de un producto, la copia de un modelo, la reproducción de un libro, de un disco o de un videocasete afecta necesariamente al comercio. Por otra parte, los derechos de la propiedad intelectual han sido precisamente concebidos para producir estos efectos. Esto no basta para incluirlos en el ámbito del art. 113. En efecto, los derechos de la propiedad intelectual no se refieren específicamente a los intercambios internacionales: afectan tanto o más al comercio interno que al comercio internacional ${ }^{17}$.

El Dictamen 2/15 toma como punto de partida la sentencia Daiichi Dankyo, que declaró que las normas contenidas en el Acuerdo ADPIC anejo al Acuerdo OMC forman parte del ámbito de la $\mathrm{PCC}^{18}$. En efecto, contrariamente a su tesis anterior, entendió que el ADPIC presenta un vínculo específico con el comercio internacional, ilustrándolo con el hecho de que el Entendimiento sobre Solución de Diferencias también autoriza la suspensión cruzada de concesiones entre el ADPIC y los demás acuerdos multilaterales principales que componen el Acuerdo de la OMC. Además, en dicha sentencia, el TJUE no consideró relevante la alegación de varios Estados miembros en el sentido de que las disposiciones sobre la existencia, el alcance y el ejercicio de los derechos de propiedad intelectual están comprendidas en el ámbito del mercado interior, con arreglo a los arts. 114 TFUE y 118 TFUE, es decir,

16 Conclusiones antes cit., punto 56.

17 Dictamen 1/94, cit., apdo. 57.

18 Sentencia de 18 de julio de 2013, cit., apdos. 52 y ss. 
en un ámbito de competencia compartida. El TJUE señaló a este respecto que las disposiciones del ADPIC «se inscriben en el marco de la liberalización del comercio internacional, y no en el de la armonización de las legislaciones de los Estados miembros de la Unión», sin perjuicio, claro está, de que las normas comunes que pueda adoptar la UE en esta materia deban respetar las normas contenidas en aquel (apdo. 59) ${ }^{19}$, afirmación que repite en el Dictamen 2/15 en relación con el Acuerdo con Singapur (apdo. 126).

En Daiichi el TJUE se refirió asimismo a los cambios introducidos en el antiguo art. 133 TCE por el Tratado Lisboa, precepto que, a diferencia del actual art. 207.1 TFUE, no mencionaba siquiera «los aspectos comerciales de la propiedad intelectual e industrial», subrayando que estos términos se corresponden con el propio título del ADPIC. Descartaba por ello que fueran pertinentes sus pronunciamientos anteriores a 2009, entre los que cabe citar, además del Dictamen 1/94, su sentencia de 2007 en el asunto Merck Genéricos Productos Farmacéuticos ${ }^{20}$.

Sin embargo, por mucho que el cambio introducido en el art. 207.1 por el Tratado de Lisboa sea relevante (que sin duda lo es), lo cierto es que la sentencia Daiichi o el Dictamen 2/15 se apartan del razonamiento del Dictamen 1/94 («los derechos de la propiedad intelectual no se refieren específicamente a los intercambios internacionales: afectan tanto o más al comercio interno que al comercio internacional») sin explicar su cambio de opinión, que bien podría haber justificado en un re-examen del contenido del ADPIC basado en estudios o informes de expertos.

El Dictamen resulta asimismo parco en su argumentación cuando descarta que la remisión que hace el capítulo 11 al Convenio de Berna para la Protección de las Obras Literarias y Artísticas y a los Tratados de la OMPI sobre Derechos de Autor y sobre Interpretación y Ejecución y Fonogramas incida en la calificación que, desde el punto de vista de las competencias de la UE, merecen sus disposiciones. A este respecto, la AG, en línea con las alegaciones de algunos Estados miembros, había señalado en sus conclusiones que los derechos morales (derecho de paternidad y derecho de integridad) regulados en dichos tratados internacionales tienen también un carácter claramente no económico, excluyendo por ello que todo el capítulo pudiera considerase comprendido dentro del ámbito de la PCC (punto 456). Frente a esta posición, el TJUE se contenta con afirmar que "la remisión que el Acuerdo proyectado realiza a estos convenios no basta, a efectos de determinar la naturaleza de la competencia de la Unión para celebrar el Acuerdo proyectado, para conside-

19 Ibid., apdos. 59- 60.

20 Sentencia de 11 de septiembre de 2007, C-431/05, ECLI:EU:C:2007:496. 
rar que esta materia constituye plenamente un componente de este, que no menciona los derechos morales» (apdo. 129, cursiva añadida), destacando que el «objeto esencial» del Acuerdo es facilitar y regular el comercio entre la UE y Singapur (apdo. 130). No cuestiono la conclusión, pero el dictamen parece exigir del lector un acto de fe.

\section{DISPOSICIONES SOBRE DERECHO DE LA COMPETENCIA Y SOBRE CONTRATACIÓN PÚBLICA}

Resulta bastante evidente, a mi entender, que las disposiciones del Acuerdo en materia de contratación pública (capítulo 10) y de derecho de la competencia (capítulo 12) tienen por objeto la liberalización del comercio entre la UE y Singapur y que pueden producir efectos directos e inmediatos en dicho comercio. En relación con el capítulo sobre competencia, el TJUE advierte que «la lucha contra las actividades contrarias a la competencia y contra las concentraciones [..] tienen por objeto o efecto impedir que el comercio entre la Unión y ese tercer Estado se desarrolle en condiciones de competencia sanas» (apdo. 134). Y respecto del primer capítulo, explica que su objeto no es otro que el de facilitar el acceso de los operadores económicos de ambas partes a los mercados públicos en condiciones no discriminatorias y efectivas (apdos. 75 y ss.). Partiendo de estas asunciones (que, no por ser seguramente obvias, dejan de merecer una motivación más extensa), y tras recalcar que en ningún caso el Acuerdo persigue armonizar las legislaciones internas de las partes, el dictamen concluye que ambos capítulos entran dentro del campo del art. 207.1 del TFUE (apdos. 75 y ss., y 35 y ss.). No obstante, excluye la contratación pública en el ámbito de los transportes, materia que considera comprendida dentro del ámbito de la competencia de la UE en dicho sector (véase infra epígrafe 3).

El dictamen confirma en este punto que la inclusión en los ALC de nueva generación de disposiciones en estas materias responde efectivamente a consideraciones de política comercial. No podemos, sin embargo, dejar de recordar que en su sentencia de 7 de maro de 1999 en el asunto Parlamento/ Consejo, el TJUE declaró que el antiguo art. 113 del TCEE no era una base jurídica suficiente para celebrar un acuerdo con Estados Unidos en materia de contratación pública, ni para adoptar una decisión por la que se ampliaban los beneficios de la Directiva 90/531/CEE sobre contratación pública a este país, por cuanto tanto el acuerdo como la decisión afectaban a otros modos de suministro distintos de la prestación transfronteriza de servicios ${ }^{21}$, siendo así que dichos modos no estaban entonces incluidos en el ámbito de la PCC.

21 As. C-360/93, ECLI:EU:C:1996:84, apdo. 30. 


\section{DESARROLLO SOSTENIBLE}

En relación con el capítulo 13 sobre desarrollo sostenible, el TJUE parte de la constatación de que «la extensión del ámbito de la política comercial común por el Tratado FUE constituye una evolución significativa del Derecho primario de la Unión» (apdo. 142), evolución que se caracteriza, entre otras cosas, por la exigencia contenida en el art. 207.1 de que la PCC se lleve a cabo «en el marco de los principios y objetivos de la acción exterior de la Unión» (véanse en el mismo sentido los arts. 21.3 TUE y 205 TFUE). Estos principios y objetivos incluyen, conforme al art. 21.2.f) TUE, «contribuir a elaborar medidas internacionales de protección y mejora de la calidad del medio ambiente y de la gestión sostenible de los recursos naturales mundiales, para lograr el desarrollo sostenible». El TJUE recuerda asimismo los arts. 9 y 11 TFUE, que exigen que en la definición y ejecución de sus políticas y acciones la UE tenga en cuenta las exigencias relacionadas con «la garantía de una protección social adecuada» y la protección del medio ambiente «en particular con objeto de fomentar un desarrollo sostenible». También el art. 3.5 TUE que dispone que, en sus relaciones con el resto del mundo, la Unión contribuirá a un "comercio libre y justo». De todo ello, el TJUE deduce que las disposiciones del Acuerdo relativas al desarrollo sostenible, a la protección social de los trabajadores y a la protección del medio ambiente están incluidos en el ámbito de la PCC (apdo. 167).

Refiriéndose ya al Acuerdo, el TJUE constata que, en virtud de las disposiciones de su capítulo 13, las partes se comprometen a garantizar que los intercambios comerciales se realicen dentro del respeto a los tratados internacionales en materia de protección social y del medio ambiente de los que son parte. Pues bien, señala a este respecto que el hecho de que estos tratados abarquen no solo los intercambios comerciales entre la UE y Singapur no altera su conclusión pues, en síntesis, el capítulo 13 del Acuerdo «no atañe ni al alcance de los convenios internacionales a los que hace referencia ni a las competencias de la Unión o de los Estados miembros relativas a esos convenios». Afirma asimismo que dicho capítulo presenta un vínculo específico con el comercio entre la UE Singapur y puede producir efectos directos e inmediatos en él (apdos. 155 y 156), como así lo demuestra el hecho de que se prevea la posibilidad de que cualquiera de las partes finalice o suspenda la liberalización de dicho comercio en caso de infracción de sus disposiciones (apdo. 161, que se refiere a la facultad de suspensión de un tratado prevista en el art. 60.1 de la Convención de Viena de 1969 en tanto que norma consuetudinaria aplicable a las relaciones entre la UE y los terceros Estados).

Parece evidente que, como señala la AG en sus conclusiones (haciendo suyas las alegaciones de la Comisión), diferencias significativas en los 
niveles de protección ambiental y social pueden falsear la competencia y el comercio (punto 478). Sin embargo, la AG es de la opinión de que un número importante de disposiciones del capítulo 13 no imponen ningún tipo de condición al comercio (que faculte a la otra parte para adoptar sanciones comerciales), ni regula de otro modo el uso de instrumentos de política comercial como medio para promover el desarrollo sostenible (punto 491), sino que "pretenden básicamente establecer en la Unión y en Singapur normas mínimas sobre protección laboral y protección medioambiental» (punto 491). La AG considera por ello que forman parte del ámbito de las competencias compartidas entre la UE y sus Estados miembros, y no de la PCC. El TJUE, sin embargo, se contenta con afirmar que el capítulo no tiene por objeto determinar los niveles de protección social y medioambiental en el territorio respecto de las partes (apdo. 166), sin motivar su afirmación.

\section{DISPOSICIONES EN MATERIA DE TRANSPORTES $Y$ «DOCTRINA AETR»}

Como ya indicamos anteriormente, el Dictamen aborda el análisis de los preceptos del Acuerdo referidos a los transportes desde la perspectiva de la «doctrina AETR» consagrada en el art. 3.2 del TFUE. Con arreglo a este precepto, la UE tendrá competencia exclusiva para la celebración de un acuerdo internacional «en la medida en que pueda afectar a normas comunes a alterar el alcance de las mismas» (cursiva añadida). Y a este respecto el TJUE concluye que las disposiciones sobre transportes marítimos, ferroviarios y por carretera pueden efectivamente afectar a normas comunes adoptadas por la UE (en particular, a las normas contenidas en el Reglamento 4055/86 sobre libre prestación de servicios en el ámbito de transporte marítimo entre Estados miembros y entre Estados miembros y Estados terceros; en la Directiva 2012/34 por la que se establece un espacio ferroviario europeo único, y en los Reglamentos 1071/2009, 1072/2009 y 1073/2009 sobre transportes por carretera). El Dictamen discrepa, pues, de la $A G$ en lo que se refiere a las disposiciones sobre transportes marítimos (puntos 236 ss. de sus conclusiones). La AG entendía que corresponden a un ámbito de competencia compartida en la medida en que, a su juicio, la celebración del Acuerdo con Singapur resulta necesaria para alcanzar un objetivo de la UE en el contexto de la PCT, en el sentido del art. 216.1 del TFUE (punto 243).

El Dictamen 2/15 reitera la jurisprudencia anterior del TJUE en el sentido de que: a) el riesgo de que un acuerdo internacional afecte a una norma común o altere su alcance existe cuando los compromisos que recoge están 
«comprendidos en el ámbito de aplicación de esas normas»; b) no es necesario para ello que exista «una concordancia completa entre el ámbito abarcado por los compromisos internacionales y el abarcado por la normativa de la Unión», sino que basta con que los compromisos "pertenezca a un ámbito ya cubierto en buena medida por esas normas», y c) cuando un acuerdo establezca «la aplicación a las relaciones internacionales reguladas por tal acuerdo de normas que se solapan, en gran medida, con las normas comunes de la Unión aplicables a las situaciones intracomunitarias, debe considerarse que ese acuerdo puede afectar a esas normas comunes o alterar el alcance de las mismas» a pesar de que no exista contradicción entre ellas ${ }^{22}$.

$\mathrm{Y}$ en lo que hace al transporte por vías navegables interiores, tras constatar que el Acuerdo contiene compromisos de alcance extremadamente limitado, que no comportan su liberalización ni en el territorio de los Estados miembros de la UE ni en de Singapur, el Dictamen recuerda que, de acuerdo con su jurisprudencia ${ }^{23}$, «al examinar la naturaleza de la competencia para celebrar un acuerdo internacional, no deben tenerse en cuenta disposiciones de ese acuerdo que tengan un alcance extremadamente limitado» (apdo. 217). Esta jurisprudencia es en cambio ignorada por la $A G$, quien en sus conclusiones propone considerar las disposiciones sobre transporte por vías navegables como un ámbito de competencia compartida en virtud del art. 216.1 TFUE (punto 246).

El Dictamen también considera excluidas del ámbito de la PCC - como vimos - las disposiciones del Acuerdo sobre contratación pública relativas a los servicios de transporte, así como los contratos de servicios ligados se forma inherente a estos servicios. Y respecto de ellas, y a diferencia de la AG (puntos 47-408), entiende igualmente que la competencia de la UE es exclusiva en la medida en que están comprendidas en un ámbito ya cubierto en gran parte por normas comunes de transportes (en particular las Directivas 2014/24/UE, sobre contratación pública, y 2014/25/UE, sobre contratación en los sectores del agua, la energía, los transportes y los servicios postales) (apdos. 222 y ss.).

22 Véase, entre otros, el Dictamen 1/13 sobre el Convenio sobre los aspectos civiles de la sustracción internacional de menores, de 14 de octubre de 2014, ECLI:EU:C: 2014:2303, apdos. 71-73 y 84-90, y el Dictamen 3/15, cit., apdos. 105-107. Para un análisis de la última jurisprudencia del TJ en esta materia, véase Friedrich ERLBACHER, «Recent Case Law on External Competences of the European Union: How Member States Can Embrace Their Own Treaty», Cleer Papers, 2017/2, pp. 24 y ss.

Por todos, Dictamen 1/08, cit., apdo. 166. 


\section{PROTECCIÓN DE INVERSIONES}

\section{LA POSICIÓN INICIAL DE LA COMISIÓN}

El aspecto sin duda más controvertido en relación con la competencia de la UE para celebrar el Acuerdo con Singapur y, en general, cualquier ALC de nueva generación, es el alcance de la competencia que el art. 207.1 del TFUE le atribuye en materia de inversiones extranjeras. Como es bien sabido, el Tratado de Lisboa incluyó en dicho precepto (antiguo art. 133.1 del TCE) - y, en consecuencia, como parte de la competencia exclusiva de la UE en materia de PCC — una referencia a las «inversiones extranjeras directas». También es sabido que los nuevos ALC incluyen capítulos sobre inversiones que pretenden sustituir a los acuerdos bilaterales de protección de inversiones celebrados por los Estados miembros, cuyo mantenimiento ha permitido con carácter transitorio el Reglamento 1219/2012.

En su comunicación de 2010 titulada «Hacia una política global europea en materia de inversión internacional sobre protección de inversiones ${ }^{24}$, la Comisión descartaba una interpretación restrictiva del art. 207 TFUE y sostenía que la competencia exclusiva de la UE alcanza todos los aspectos relativos al "postestablecimiento», incluida la articulación de mecanismos de solución de controversias entre el Estado de inversión y los inversores extranjeros. Más aun, la Comisión llegaba a afirmar que solo la UE puede actuar como demandada en un arbitraje de inversiones incluso cuando la medida contestada por el inversor extranjero haya sido adoptada por un Estado miembro. El Consejo de la UE ha venido en cambio entendiendo que los acuerdos sobre protección de inversiones exceden el ámbito de la competencia exclusiva de la UE en los ámbitos antes señalados, como así se refleja en los mandatos de negociación de los nuevos ALC. Consecuentemente, comparte la opinión defendida por parte de la doctrina de que los acuerdos sobre inversiones de la UE deben adoptar la forma de acuerdos mixtos ${ }^{25}$.

En contra de la opinión de la Comisión, se ha argumentado que la referencia en el art. 207 TFUE a las inversiones «directas» excluye las inversiones "en cartera», cuya protección aseguran la mayoría de los APPRI. También que la competencia de la UE solo se extiende a los aspectos comerciales relacionados con las inversiones, dejando fuera, en principio, su protección. Bien es

$24 \operatorname{COM}(2010) 343$ final, de 7 de julio de 2010.

25 Esta opinión también la hizo suya el Tribunal Constitucional Federal Alemán en su sentencia de 30 de junio de 2009 sobre el Tratado de Lisboa, BVERFG, 2 BE 2/08, apdo. 379 . 
cierto que, en relación con este segundo aspecto, generalmente se admite que no es posible una división clara entre las fases "preestablecimiento" $\mathrm{y}$ "postestablecimiento» en la medida en que la realización efectiva de una inversión exterior viene en la práctica determinada por el tratamiento y la seguridad jurídica que se ofrece al inversor. A este respecto, cabe recordar que era generalmente admitido que el antiguo art. 57.2 TCE (actual art. 64.2 TFUE) atribuía implícitamente una competencia externa para celebrar acuerdos en materia de libre circulación de capitales que supongan inversiones directas que incidieran en la fase postacceso al mercado. Así lo ponía de relieve el Minimum Platform on Investment for EU FTAs, aprobado por el Consejo de la UE en 2006, en el que se señalaba que las disposiciones en materia de establecimiento para los acuerdos de libre comercio debían abarcar no solo el acceso al mercado sino igualmente el reconocimiento en favor de los inversores del derecho al trato nacional y al trato de la nación más favorecida ${ }^{26}$.

\section{LA POSICIÓN DEL TJUE DE JUSTICIA RESPECTO DE LAS «INVERSIONES DIRECTAS»}

En su dictamen el TJUE aborda separadamente el alcance la competencia de la UE respecto de las inversiones directas e indirectas. El TJUE comienza recordando (apdo. 80) que, de acuerdo con su propia jurisprudencia, por inversión directa se entiende «cualquier tipo de inversión efectuada por personas físicas o jurídica y que sirva para crear o mantener relaciones duraderas y directas entre el proveedor de fondos y la empresa a la que se destinan dichos fondos para el ejercicio de una actividad económica» y que, por lo que respecta a las participaciones en empresas nuevas o existentes, «el objetivo de crear o mantener vínculos económicos duraderos presupone que las acciones que posee el accionista le ofrecen, ya sea en virtud de las disposiciones de la legislación nacional sobre las sociedades por acciones, o de otra forma, la posibilidad de participar de manera efectiva en la gestión o el control de dicha sociedad ${ }^{27}$. Así pues, las inversiones en forma de adquisición de títulos en el mercado de capitales efectuada con la única intención de realizar una inversión, pero sin pretender influir en la gestión y el control de la empresa, no son inversiones directas sino lo que se denomina inversiones "en cartera ${ }^{28}$.

26 Doc. del Consejo 15375/06, de 27 de noviembre de 2006.

27 Por todas, sentencia de 12 de diciembre de 2006, Test Claimants, C-446/04, ECLI:EU:C:2006:774, apdos. 181-182.

28 Por todas, sentencia de 10 de noviembre de 2011, Comisión /Portugal, C-212/09, ECLI:EU:C:2011:717, apdo. 47. 
Pues bien, tras recordar su propia distinción entre inversiones directas y en cartera, el TJUE afirma en el Dictamen 2/15 que «el hecho de que los autores del Tratado FUE utilizaran la expresión «inversiones extranjeras directas» en el art. 207 TFUE, apartado 1, manifiesta sin ambigüedad su voluntad de no incluir otras inversiones extranjeras en la política comercial común", concluyendo que las últimas no están comprendidas en el campo de la PCC (apdo. 83).

Y en relación con las inversiones directas, advierte que "cualquier acto de la Unión que promueva, facilite o regule la participación de una persona física o jurídica de un tercer Estado en la Unión —o a la inversa— en la gestión y control de una sociedad que ejerza una actividad económica puede producir efectos directos e inmediatos en el comercio entre dicho Estado y la Unión", descartando en cambio este vínculo específico con el comercio en el caso de las inversiones que no dan lugar a una participación de este tipo (apdo. 84). Debe advertirse que, de acuerdo con este razonamiento, la competencia de la UE en el ámbito de la PCC incluiría a las inversiones extranjeras directas, aun cuando nada dijera al respecto el art. 207.1 TFUE. En otras palabras, antes del Tratado de Lisboa, las disposiciones de un acuerdo que afectara a las inversiones directas debían — de acuerdo con esta doctrina- situarse en el ámbito del antiguo art. 133 TCE, y no en del mencionado art. 57.2 (actual art. 64.2 TFUE).

Sin embargo, como era previsible, el Consejo y algunos Estados miembros alegaron durante el procedimiento que la referencia a las inversiones directas en el art. 207.1 TFUE abarca su admisión (acceso al mercado), pero no en cambio su protección, destacando que este último es precisamente el objeto del capítulo 9 del Acuerdo proyectado. El TJUE, sin embargo, subraya que el precepto no establece una distinción en función de que se trate de actos que tenga por objeto la admisión o la protección de las inversiones (apdo. 87). Por otra parte, afirma que los compromisos en materia de protección de inversiones que se recogen en el Acuerdo (básicamente las obligaciones de trato nacional, de trato justo y equitativo, de indemnización en caso de expropiación y de libre transferencia de dividendos, presentes en todos los APPRI), contribuyen a la seguridad jurídica de los inversores y, en consecuencia, tienen por objeto promover, facilitar y regular el comercio entre la Unión y Singapur en el sentido de la jurisprudencia Daïchi (apdo. 94) y pueden producir efectos directos e inmediatos en dicho comercio (apdo. 95).

En sus conclusiones, la AG recordaba a este respecto que en su Dictamen 1/08 el TJUE afirmó que la competencia exclusiva de la CE en materia de comercio de servicios ex art. 133 TCE ya incluía la regulación contenida en el AGCS en relación con el modo 2 de suministro de servicios (que con carácter general se corresponde con el establecimiento), regulación que afecta no solo 
al acceso al mercado sino igualmente al trato a dispensar una vez establecida la presencia comercial. Por otra parte, afirmaba que, en la actualidad, la «inversión y el comercio son componentes esenciales de una política comercial común unificada y efectiva», advirtiendo que «en una economía cada vez más globalizada, debe asumirse que las decisiones que se adoptan sobre los mercados de exportación e importación y sobre dónde producir dependen en ambos casos de las políticas y de la normativa sobre comercio e inversión» (punto 329). A este respecto, la AG invocó la nota del Praesidium al proyecto de artículos sobre la acción exterior del Tratado Constitucional, en la que se advertía que la inclusión de una referencia a las inversiones directas en el precepto que, tras el Tratado de Lisboa, pasaría a ser el art. 207.1 TFUE constituía «un reconocimiento del hecho de que los flujos financieros completan el comercio [de] mercancías y constituyen hoy en día una parte considerable de los intercambios comerciales ${ }^{29}$.

El Dictamen 2/15 también rechaza las alegaciones formuladas por el Consejo y algunos Estados miembros en el sentido de que determinadas disposiciones del capítulo 9 afectan a competencias exclusivas de estos últimos. Entre ellas figuran, a juicio de estos, por una parte, la posibilidad de que las partes otorguen un trato menos favorable a los inversores de la otra parte en la medida en que sea necesario para mantener el orden público y la seguridad pública o para salvaguardar otros interés públicos, a menos que la medida constituye una restricción encubierta o las disposiciones relativas a la propiedad privada (posibilidad de expropiación y obligación de indemnizar) y, por otra, la aplicación a los inversores extranjeros de las respectivas disposiciones en materia penal, fiscal o de seguridad social. Así, en relación con estas últimas el TJUE entiende que ninguna de ellas establece obligaciones para los Estados miembros, sino que se limitan a exigir a las partes a que actúen en dichos ámbitos de forma equitativa y no discriminatoria (apdos. 105 y ss.). Y respecto de la posibilidad de otorgar un trato menos favorable por las razones expuestas anteriormente, entiende que el Acuerdo tan solo contempla la posibilidad de aplicar una excepción condicionada al cumplimiento de los requisitos de necesidad y de que no se trate de una restricción encubierta, siendo esta limitación, a su juicio y siguiendo a la AG, inherente a la realización de los intercambios comerciales (apdo. 102).

Por lo que se refiere a las disposiciones relativas a la propiedad privada (posibilidad de expropiación y obligación en tal de caso de indemnizar) y, en concreto, al art. 345 del TFUE invocado por el Consejo y los Estados miembros, el TJUE advierte que, de acuerdo con su jurisprudencia anterior,

29 CONV 685/03, de 22 de abril de 2003, p. 52. 
la neutralidad exigida a la UE por dicho precepto en relación con los regímenes de propiedad privada «no produce el efecto de sustraer los regímenes de propiedad existentes en los Estados miembros a las reglas fundamentales del Tratado FUE, entre las que se encuentran, en particular, las de no discriminación $[\ldots] »^{30}$. Sigue en ello a la AG, quien en sus conclusiones advertía que, en definitiva, el régimen de propiedad no está excluido del ámbito de aplicación del derecho de la UE ni excluye toda actuación de la UE en esta materia (punto 340, en el que cita la sentencia de 13 de julio de 1996, España/Consejo ${ }^{31}$ ). Hace años mantuve una posición contraria ${ }^{32}$, pero admito que los argumentos del TJUE y de la AG me han resultado convincentes ${ }^{33}$.

\section{LAS INVERSIONES «EN CARTERA»}

Por lo que se refiere a las inversiones en cartera, tras descartar, como ya hemos dicho, que las disposiciones referidas a ellas entren dentro del ámbito de la PCC, el TJUE descarta igualmente que formen parte de una competencia exclusiva de la UE en virtud del art. 3.2 TFUE. El TJUE considera, en particular, que puedan «afectar a normas comunes o alterar el alcance de las mismas», al no existir actos de derecho derivado en este ámbito.

A favor del juego de la «doctrina AETR», la Comisión invocó el art. 63 TFUE, que prohíbe las restricciones a los movimientos de capitales y sobre los pagos entre Estados miembros y entre Estados miembros y terceros países. El TJUE, sin embargo, no comparte que la expresión «normas comunes» incluya disposiciones de derecho primario (apdos. 229 y ss.). En este mismo sentido, la AG trajo a colación los Dictámenes 2/92 y 1/94, en los que el TJUE señaló, respectivamente, que «una competencia interna solo puede engendrar una competencia externa exclusiva si se ejercita ${ }^{34}$ y que «la competencia externa

30 Sentencia de 22 de octubre de 2013, Essent, C-105/12 a C-107/12, ECLI:EU:C: 2013:677, apdos. 29 y 36.

31 As. C-350/92, ECLI:EU:C:1995:237, apdo. 22.

32 Javier DÍEZ-HOCHLEITNER, «El incierto futuro de los acuerdos bilaterales sobre protección de inversiones celebrados por los Estados miembros de la UE», Revista Española de Derecho Europeo, núm. 33, 2010, pp. 5-43 (p. 34).

33 En el mismo sentido que el TJ se había pronunciado en esta misma revista Luis M. HINOJOSA MARTÍNEZ en «El alcance de la competencia exterior europea en materia de inversiones», Revista de Derecho Comunitario Europeo, 52, 2015, pp. 871907 (en pp. 889 y ss.).

34 Dictamen 2/92 sobre la Decisión del Consejo relativa a la participación de la Comunidad en la Tercera Decisión revisada del Consejo de la OCDE relativa al trato nacional, de 24 de marzo de 1995, ECLI:EU:C:1995:83, apdo. 36. 
exclusiva de la Comunidad no se desprende ipso facto de su facultad de dictar normas en la esfera interna ${ }^{35}$.

El TJUE también excluye que la inclusión en el capítulo 9 de las inversiones en cartera fuera "necesaria» para permitir a la UE «ejercer su competencia interna» (segundo supuesto contemplado en el art. 3.2 TFUE), como admitió la propia Comisión en sus observaciones. Pero estima, en cambio, que la celebración de un acuerdo relativo a tales inversiones puede resultar «necesaria para alcanzar, en el contexto de las políticas de la Unión, alguno de los objetivos establecidos en los Tratados», en el sentido del art. 216 TFUE, apartado 1 (apdo. 239).

En otras palabras, el TJUE concluye que las previsiones sobre inversiones en cartera corresponden al ámbito de las competencias compartidas a que se refiere el art. 216.1. Y, en efecto, «puesto que la libre circulación de capitales y de pagos entre los Estados miembros y los terceros Estados, prevista por el art. 63 TFUE, no es oponible formalmente a los terceros Estados, la celebración de acuerdos internacionales que contribuyan al establecimiento de esa libre circulación sobre una base recíproca puede considerarse necesaria para realizar plenamente esta libre circulación, que es uno de los objetivos [...] del Tratado FUE» (apdo. 240).

En este punto quiere reiterar que el TJ parte de una clara distinción entre los supuestos contemplados en segundo lugar en el art. 216.1 del TFUE (que la celebración del acuerdo sea necesaria para lograr uno de los objetivos de la UE) y en el art. 3.2 del mismo Tratado (que sea necesaria para ejercer una competencia interna). Si bien cabe entender que esta distinción estaba presente en su jurisprudencia anterior al Tratado de Lisboa ${ }^{36}$, a mi juicio no se evidencia con plena nitidez hasta después ${ }^{37}$.

En otros orden de consideraciones, me sorprende que el Dictamen no se refiera a las sentencias de 2009 por las que el TJUE condenó a Austria, Suecia y Finlandia por considerar que determinados APPRI celebrados por ellos con terceros países resultaban contrarios al antiguo Tratado $\mathrm{CE}^{38}$. En

35 Dictamen 1/94, cit., apdo. 77.

36 Véanse, por ejemplo, el Dictamen 1/94, cit., apdo. 89, o la sentencia de 5 de noviembre de 2002, Comisión c. Dinamarca, C-467/98, ECLI:EU:C:2002:625, apdo. 57.

37 Dictamen 1/03 sobre el Convenio de Lugano, de 7 de febrero de 2006, ECLI:EU:C: 2006:81, apdos. 114 y ss.

38 Sentencia de 3 de marzo de 2009, Comisión/Austria, C-205/06, ECLI:EU:C:2009:118, apdos. 37 ss.; y sentencias de 19 de noviembre de 2009, Comisión/Suecia, C-249/06, ECLI:EU:C:2009:119， y Comisión/Finlandia, C-118/07, ECLI:EU:C:2009:715, apdos. 37 y ss., y 30 y ss., respectivamente. 
concreto, el TJUE declaró que las disposiciones de dichos APPRI relativas a la libre transferencia de capitales eran incompatibles con los antiguos arts. 57.2, 59 y 60.1 TCE (con algunos cambios, actuales arts. 64.2, 66 y 215.1 TFUE), que atribuían competencia al Consejo para restringir, en determinados supuestos concretos, los movimientos de capitales y los pagos entre los Estados miembros y los Estados terceros. Pues bien, entiendo que la incompatibilidad apreciada en estas sentencias comportaría la imposibilidad para los Estados miembros de celebrar por si mismos acuerdos sobre protección de inversiones que incluyan disposiciones como las consideradas en ellas. Y me sorprende que el TJUE las ignore aun cuando no comparto la opinión expresada en ellas ${ }^{39}$, por las razones que expuso el AG Poiares Maduro $^{40}$.

\section{EL ACCESO AL ARBITRAJE DE INVERSIONES POR LOS INVERSORES DE LAS PARTES}

Particular interés presentan las consideraciones que realiza el TJUE en relación con las disposiciones del capítulo 9 que articulan el mecanismo de solución de diferencias entre un inversor de una parte y otra parte. Al igual que la mayoría de los APPRIs vigentes, el capítulo 9 del Acuerdo contempla el posible recurso al arbitraje por parte de los inversores de una parte que consideren que la otra parte ha incumplido las obligaciones sobre protección de sus inversiones asumidas en él. En concreto, el Acuerdo con Singapur sigue el modelo «no-u-turn», permitiendo a los inversores de cada parte presentar reclamación arbitral aun cuando ya hubieran entablado procedimientos ante los tribunales internos, siempre que renuncien a los procedimientos en curso y a iniciar otros nuevos. Por otra parte, pone a disposición de los inversores el arbitraje CIADI o con arreglo al Mecanismo Complementario del CIADI (para el caso de que la parte demanda no esté vinculada por el Convenio de Washington) y el arbitraje ad hoc conforme a las reglas de UNCITRAL.

Sin embargo, el TJUE resuelve en este punto con una simplicidad pasmosa, limitándose a observar, en contra de la opinión de la AG (punto 523) que «un régimen de esta índole, que sustrae diferencias a la competencia jurisdiccional de los Estados miembros, no puede tener carácter meramente instrumental en el sentido de la jurisprudencia recordada en el apartado 276 del presente dictamen, y, en consecuencia, no puede establecerse sin el con-

39 Javier DÍEZ-HOCHLEITNER, "El incierto futuro...», cit., pp. 12 y ss.

40 Conclusiones de 10 de julio de 2008 a los asuntos Comisión/Austria, C-205/06, y Comisión/Suecia, C-249/06, ECLI:EU:C:2008:391, puntos 25 y ss. 
sentimiento de éstos» (apdo. 292), lo que aboca indefectiblemente a la configuración del Acuerdo como mixto.

La jurisprudencia referida en dicho apdo. 276 del Dictamen no es otra que aquella que establece que la competencia de la UE para contraer compromisos internacionales incluye la de acompañar esos compromisos de disposiciones institucionales, accesorias por su naturaleza ${ }^{41}$. Esta jurisprudencia también le lleva a considerar que las demás disposiciones institucionales del Acuerdo relacionadas con ámbitos de competencia exclusiva de la UE corresponden asimismo con tales ámbitos, en tanto que las relativas a ámbitos de competencias compartidas también merecen esta consideración (apdos. 277 y ss.).

Así pues, para descartar la competencia exclusiva de la UE, el TJUE no tiene en cuenta otras consideraciones a mi juicio igualmente relevantes. En particular, no se refiere al hecho de que, de acuerdo con el propio Acuerdo y con el Reglamento 912/2014 sobre responsabilidad financiera relacionada con los mecanismos de resolución de litigios en materia de inversiones establecidos por acuerdos internacionales en los que la UE sea parte, las reclamaciones de los inversores de Singapur pueden tener como destinatarios a los Estados miembros de la UE (y no a la UE) cuando su objeto lo constituyan medidas adoptadas por estos. Más aun, no parece aventurado afirmar que este será el caso habitual dado el reparto ad intra de competencias que preside el sistema competencial de la Unión ${ }^{42}$.

No podemos olvidar a este respecto que incluso en los escasos ámbitos de competencia exclusiva de la UE, las medidas de ejecución —al menos las de carácter administrativo- corresponden normalmente a los Estados miembros, no siendo descartable que puedan resultar contrarias al propio derecho de la Unión. Pero es que en el caso de reclamaciones basadas en acuerdos de inversión normalmente entrarán en juego medidas comunitarias que dejan a los Estados miembros un margen de apreciación o ni siquiera estarán afectadas competencias de la UE. Nos referimos en particular a los casos de reclamaciones basadas en la obligación de otorgar un trato justo y equitativo (piénsese, por ejemplo, en el reciente laudo CIADI en el

41 El TJUE cita el Dictamen 1/76 relativo al Fondo de Inmovilización de la Navegación Interior, de 26 de abril de 1977, ECLI:EU:C:1977:63, apdo. 5; el Dictamen 1/78, cit., apdo. 56, y la sentencia de 22 de octubre de 2013, Comisión/Consejo, C-137/12, ECLI:EU:C:2013:675, apdos. 70-71.

42 Véase mi trabajo "The European Union Facing Investment Arbitration", en Piet EECKHOUT, Manuel LÓPEZ ESCUDERO (eds.), The European Union's External Actions in Times of Crisis, Hart Publishing, 2016, pp. 453-482 (en pp. 470 y ss.). 
caso Eiser c. España, condenando a nuestro país por los cambios regulatorios operados en 2013 y 2014 en el ámbito de las tarifas aplicables a las energías renovables $^{43}$, cambios que fueron ajenos al derecho de la UE) o que traen causa de medidas de carácter expropiatorio (tanto si se trata de expropiaciones directas como indirectas).

El problema no radica, como apuntara la $A G$ en sus conclusiones, en que en el caso de ser demandado un Estado miembro podría este tener que asumir la carga financiera derivada de un laudo desfavorable (punto 529), pues, como bien señala ella misma, en su Dictamen 1/75 sobre el Acuerdo relativo a una Norma sobre Gastos Locales elaborado en el marco de la OCDE, el TJUE ya advirtió que, para determinar si la UE es o no competente para su celebración, «importa poco que las obligaciones y las cargas financieras inherentes a la ejecución del acuerdo previsto incumban directamente a los Estados miembros» ${ }^{44}$. La cuestión es que, incluso en relación con un ámbito de competencia exclusiva como es la PCC, el apdo. 6 del art. 207 TFEU dispone que el ejercicio de las competencias atribuidas por dicho precepto «no afectará a la delimitación de las competencias entre la Unión y los Estados miembros ni conllevará una armonización de las disposiciones legales o reglamentarias de los Estados miembros en la medida en que los Tratados excluyan dicha armonización». Pues bien, si solo la UE asumiera la responsabilidad internacional por la violación del Acuerdo y solo ella pudiera actuar como demanda en el correspondiente arbitraje, podría ser condenada por medidas adoptadas por los Estados miembros en el ámbito de sus propias competencias, sin contar con poderes para ello. Es por ello que tanto el capítulo 9 como, a mi juicio, el Reglamento 912/2014 prevén la posible actuación de los Estados miembros como demandados.

Antes de concluir este epígrafe, queremos resaltar que el TJUE no se pronuncia sobre la compatibilidad del arbitraje de inversiones previsto en el Acuerdo con la autonomía del derecho de la UE, cuestión que ha sido objeto de un vivo debate ${ }^{45}$. Y no lo hace porque en su solicitud de dictamen nada preguntó la Comisión al respecto, como recalca el propio TJUE (apdo. 290), al comienzo de su Dictamen, advirtiendo que este «no prejuzga en modo alguno si el contenido de las disposiciones de este Acuerdo es compatible con el Derecho de la Unión» (apdo. 30).

\footnotetext{
43 Laudo de 4 de mayo de 2017, caso CIADI núm. ARB/13/36.

44 Dictamen de 11 de noviembre de 1975, ECLI:EU:C:1975:145, respuesta B.2.

45 Véase de nuevo «The European Union Facing Investment...» (en pp. 460 y ss.).
} 


\section{LA TERMINACIÓN DE LOS APPRI CELEBRADOS POR LOS ESTADOS MIEMBROS CON SINGAPUR}

Uno de las disposiciones más polémica del Acuerdo con Singapur, desde el punto de vista del sistema competencial de la UE, es la contenida en su art. 9.10, con arreglo al cual los APPRI celebrados por los Estados miembros (diez en total, entre los que no figura España) con Singapur, «incluidos los derechos y obligaciones derivados de ellos, dejarán de tener efecto y serán sustituidos por el presente Acuerdo». En una nota a pie de página de dicha disposición se añade que "para mayor seguridad, dichos acuerdos se considerarán terminados por el ALC UE-Singapur, a tenor del art. 59, apartado 1, letra a), de la Convención de Viena sobre el Derecho de los Tratados».

Sorprendentemente, el Dictamen afirma que esta disposición se refiere a un ámbito de competencia exclusiva de la UE al referirse a acuerdos celebrados por los Estados miembros cuyo contenido, a partir del Tratado de Lisboa, entran dentro del ámbito de la PCC (apdos. 247 y 249). El TJUE llega a esta conclusión a partir del siguiente razonamiento:

240. [...] cuando la Unión negocia y celebra con un tercer Estado un acuerdo referente a un ámbito respecto del cual ha adquirido una competencia exclusiva, sustituye a sus Estados miembros. A este respecto, ha de recordarse que, desde la sentencia de 12 de diciembre de 1972, International Fruit Company y otros [...] consta que la Unión puede suceder a los Estados miembros en sus compromisos internacionales cuando los Estados miembros hayan transferido a la Unión, mediante alguno de sus Tratados constitutivos, sus competencias relativas a dichos compromisos y ésta ejerza esas competencias.

A mi juicio, sin embargo, no cabe sostener que la UE haya «sustituido» a sus Estados miembros como partes en los APPRI celebrados por ellos. Con carácter general, no es posible entender que la UE ha sucedido a sus Estados miembros en los ámbitos en que ha asumido una competencia exclusiva. No hay base para ello ni en los Tratados que rigen la Unión ni, como afirma la AG, en el derecho internacional general (punto 396). Y tampoco se deduce tal cosa de la sentencia International Fruit Company de 1972 (o de sentencias posteriores como la de 1994 en el asunto de la OCM en el sector de los plátanos). En dicha sentencia el TJUE se limitó a señalar que la asunción por la CEE de una competencia exclusiva en materia de política comercial y su ejercicio efectivo comportó que las disposiciones del GATT fueran vinculantes para ella ${ }^{46}$.

46 Sentencia de 12 de diciembre de 1972, International Fruit Company, as. ac. 21 a 24/72, ECLI:EU:C:1972:115, apdos. 10-18. 
Es verdad que un sector relevante de la doctrina, en el que cabe destacar a Pierre Pescatore, interpretó la jurisprudencia sobre el GATT de 1947 en el sentido que señala el Dictamen $2 / 15^{47}$. Y otros autores ${ }^{48}$ entendieron que, si bien el TJUE no hablaba de sucesión en la sentencia International Fruit Company, esta precisión la aportó en su sentencia de 1975 en el asunto Nederlandse Spoorwegen, en la que señaló que la CEE había «sustituido a los Estados miembros, en lo que concierne a la ejecución de los compromisos previstos por el GATT $»^{49}$. Sin embargo, estas posiciones doctrinales carecían a mi juicio de fundamento. Por lo que se refiere a la sentencia en el asunto Nederlandse Spoorwegen, una lectura detenida del texto evidencia que en ella el TJ no dijo que la CEE hubiera sucedido a los Estados miembros en el GATT de 1947, sino tan solo que los había sustituido a los efectos de su ejecución. Este es el sentido de la jurisprudencia del TJUE en relación con el GATT de 1947, como bien apunta la AG en sus conclusiones (apdos. 379-380).

También resulta llamativa la alusión que hace el TJUE (apdo. 250), en favor de su tesis, al Reglamento 1219/2012 por el que se establecen disposiciones transitorias respecto de los APPRI celebrados por los Estados miembros con terceros países. Este reglamento permite a los Estados miembros, bajo ciertas condiciones, mantener sus APPRI en vigor (e, incluso, celebrar otros nuevos) «hasta que entre en vigor un acuerdo bilateral de inversión entre la Unión y el tercer país de que se trate» (art. 3), pero en ningún modo apunta (sino al contrario) a que la UE haya sucedido a los Estados miembros en ellos.

A mi juicio, resulta evidente que solo los Estados miembros pueden proceder a la terminación de los APPRI celebrados con Singapur. Otra cosa es que, si en el ejercicio de sus competencias exclusivas, la UE celebra un acuerdo con Singapur que resulta incompatible con dichos APPRI, los Estados miembros estén obligados a su terminación, tal y como se señala en el segundo párrafo del art. 351 TFUE (véase en este sentido las conclusiones de la $A G$, puntos 389 ss.).

\section{CONCLUSIÓN}

En conclusión, más allá de las críticas que puedan formularse en relación con determinadas apreciaciones del TJUE o con la forma en que motiva algunas

47 Pierre PESCATORE, «External Relations in the Case-Law of the Court of Justice of the European Communities», Common Market Law Review, núm. 16, 1979, pp. 615645 (p. 637).

48 En este sentido, Olivier JACOT-GUILLARMOD, Droit communautaire et droit international public, Georg, Ginebra, 1979 (p. 125).

49 Sentencia de 19 de noviembre de 1975, 38/75, ECLI:EU:C:1975:154, apdo. 16. 
de sus conclusiones, comparto la consecuencia que se extrae del Dictamen 2/15 en el sentido de que el Acuerdo con Singapur debe celebrarse como acuerdo mixto. $\mathrm{O}$, con carácter general, que los ALC de nueva generación que ha impulsado la Comisión desbordan el marco de las competencias exclusivas de la UE con fundamento en el art. 207 TFUE y la «doctrina AETR».

Frente a esta realidad, deben buscarse soluciones que eviten que los nuevos acuerdos (esenciales, a mi entender, para el futuro de la UE) puedan quedar a merced de la voluntad de un solo Estado o de su opinión pública. Cabría pensar en una reforma de los Tratados que incluyera las inversiones en cartera en el ámbito de la PCC, lo que parece razonable. Sin embargo, esta reforma no podría evitar la «mixicidad» de los nuevos ALC en la medida en que contemplen el arbitraje de inversiones (aspecto nuclear de la protección de inversiones) o la terminación de los APPRI celebrados por los Estados miembros. No debe por ello descartarse que el futuro pase por desgajar los compromisos en materia de protección de inversiones de los ALC y llevarlos a acuerdos mixtos que complementen a unos ALC «puramente comunitarios». 